Phenoxazine-Based Conjugated Polymers: a New Class of Organic Semiconductors for

\title{
Field-Effect Transistors
}

Yan Zhu, Amit Babel and Samson A. Jenekhe*

Department of Chemical Engineering and Department of Chemistry, University of Washington,

Seattle, Washington 98195-1750

\section{Supporting Information}

Figure S1. ${ }^{1} \mathrm{H}$ NMR spectra of (A) PO6 and (B) POF1 and POF3.

Figure S2. FT-IR spectra of phenoxazine polymers.

Figure S3. TGA thermograms of phenoxazine-based polymers.

Figure S4. Cyclic voltammograms of POF1, POF2, and poly(9,9-dihexylfluorene) thin films in $0.1 \mathrm{M} \mathrm{Bu}_{4} \mathrm{NPF}_{6}$ solution in acetonitrile with a scan rate of $40 \mathrm{mV} / \mathrm{s}$. 


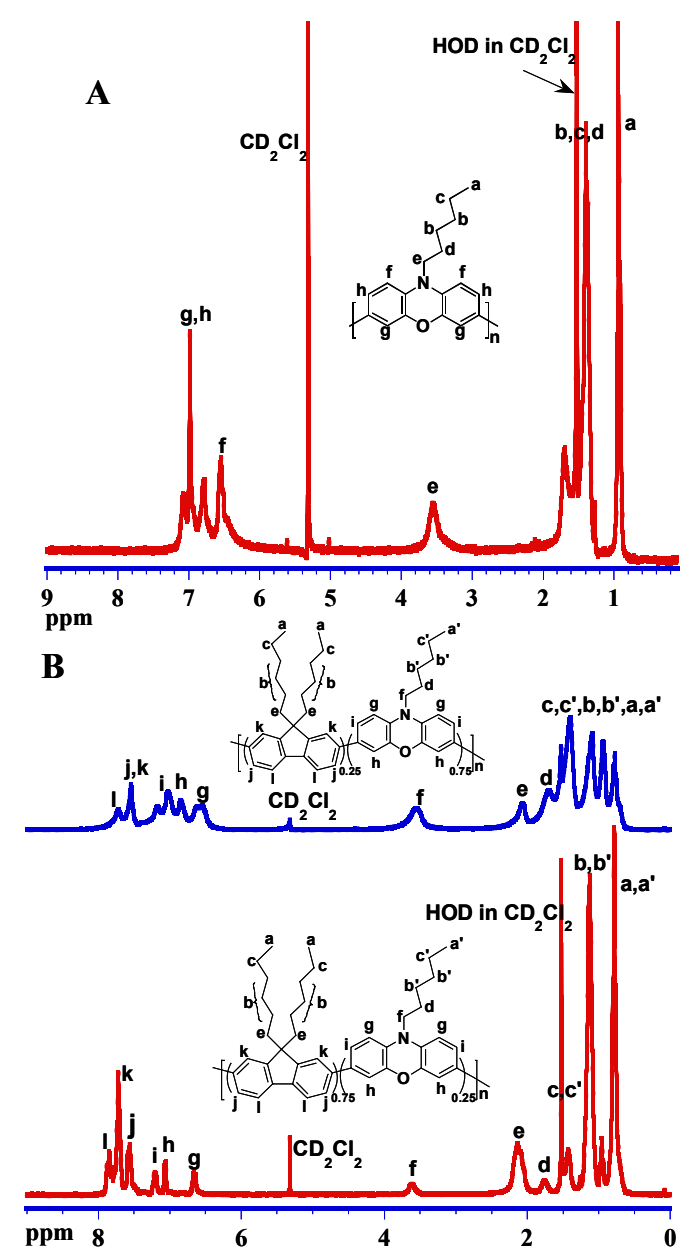

Figure S1. ${ }^{1} \mathrm{H}$ NMR spectra of (A) PO6 and (B) POF1 and POF3.

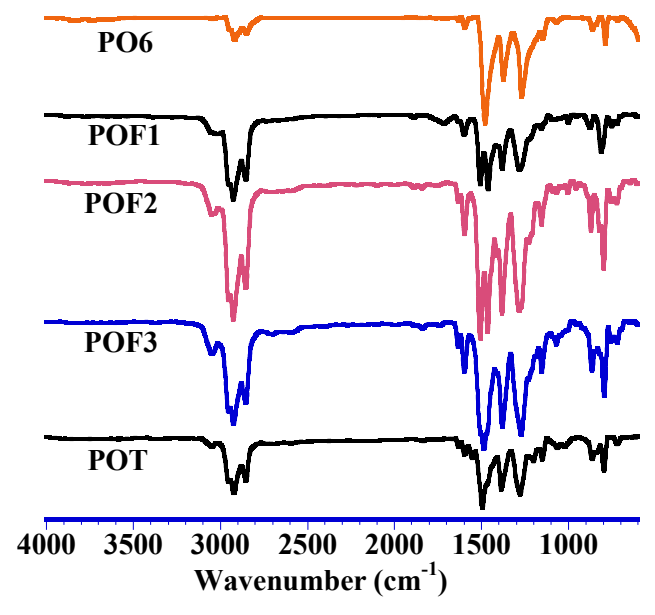

Figure S2. FT-IR spectra of phenoxazine polymers. 


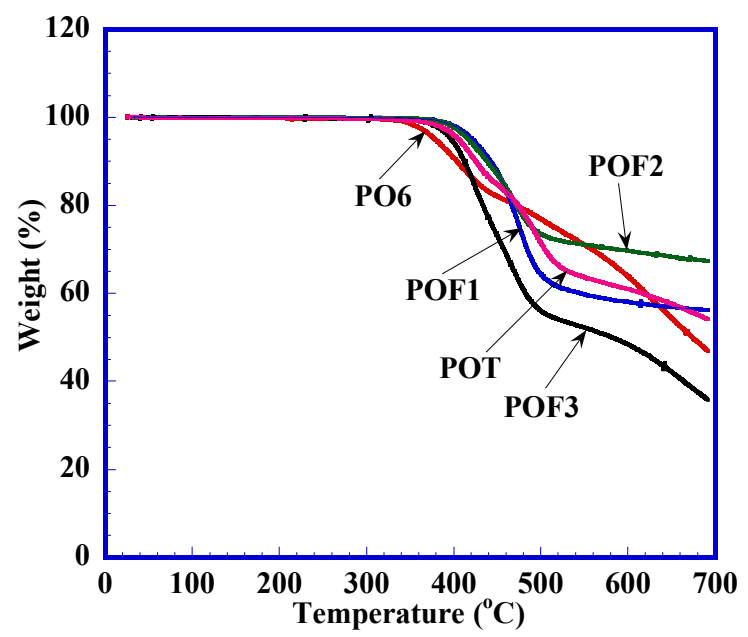

Figure S3. TGA thermograms of phenoxazine-based polymers.

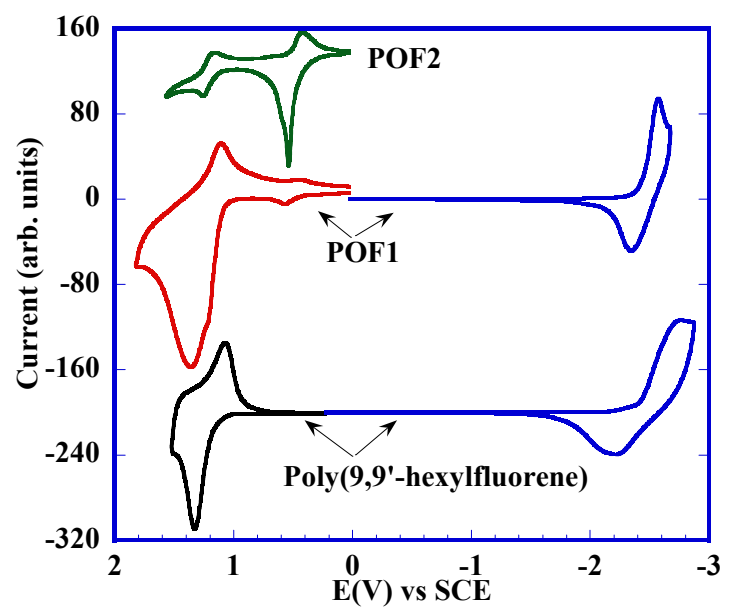

Figure S4. Cyclic voltammograms of POF1, POF2, and poly(9,9-dihexylfluorene) thin films in $0.1 \mathrm{M} \mathrm{Bu}_{4} \mathrm{NPF}_{6}$ solution in acetonitrile with a scan rate of $40 \mathrm{mV} / \mathrm{s}$. 